\title{
Assessing 3 Outbreak Detection Algorithms in an Electronic Syndromic Surveillance System in a Resource-Limited Setting
}

Emily Alsentzer, ${ }^{1}$ Sarah-Blythe Ballard,${ }^{1}$ Joan Neyra, Delphis M. Vera, Victor B. Osorio, Jose Quispe, David L. Blazes, Luis Loayza

We evaluated the performance of X-bar chart, exponentially weighted moving average, and $\mathrm{C} 3$ cumulative sums aberration detection algorithms for acute diarrheal disease syndromic surveillance at naval sites in Peru during 2007-2011. The 3 algorithms' detection sensitivity was $100 \%$, specificity was $97 \%-99 \%$, and positive predictive value was $27 \%-46 \%$.

Syndromic surveillance uses prediagnostic healthSrelated data to signal probable outbreaks warranting public health response (1). Alerta and Vigila are internet-based syndromic surveillance systems successively implemented by Peru's navy (2-4). Among other disease syndromes, individual cases of acute diarrheal disease (ADD) are self-reported to healthcare workers at sites providing care for service members, dependents, and civilian employees. We assessed the performance of $3 \mathrm{ADD}$ aberration detection algorithms in this resource-limited setting: X-bar chart, exponentially weighted moving average (EWMA), and Early Aberration Reporting System (EARS) C3 cumulative sums (CUSUM) models (5-9).

\section{The Study}

We defined ADD as $\geq 3$ loose stools within 24 hours lasting $<14$ days, epidemic threshold as the incidence of cases in excess of normal for a given period,

Author affiliations: Massachusetts Institute of Technology, Cambridge, Massachusetts, USA (E. Alsentzer); Uniformed Services University of the Health Sciences, Bethesda, Maryland, USA (E. Alsentzer, S.B. Ballard, D.L. Blazes); Johns Hopkins Bloomberg School of Public Health, Baltimore, Maryland, USA (S.-B. Ballard); Naval Medical Research Unit No. 6, Callao, Peru (S.B. Ballard, D.M. Vera, V.B. Osorio, J. Quispe); Marina de Guerra del Perú, Callao (L. Loayza)

DOI: https://doi.org/10.3201/eid2609.191315 outbreak as the detection of ADD incidence above the epidemic threshold, true outbreak as an outbreak identified by the system with confirmation by trained field personnel (e.g., enteropathogen isolation), and epidemiological silence as a period during which no cases were reported. We performed descriptive analysis of ADD cases by using data from all reporting sites during 2007-2011, then conducted subsequent analyses by using data on nonbloody ADD. We calculated ADD incidence from weekly reports from Alerta and Vigila during 2007-2011 for naval bases with population denominator data available. We compared the number of site-weeks during which $\geq 1$ ADD case was reported on shore-based sites with those of sea-based sites and nonbloody ADD incidence in summer with incidence in nonsummer months by using a MannWhitney test.

Sites with $<4$ months of epidemiologic silence during 2007-2011 (60 months) were included for outbreak detection analysis. We aggregated nonbloody ADD case counts by epidemiologic week and performed a timeseries analysis by using X-bar chart, EWMA, and modified EARS C3 CUSUM aberration detection algorithms to flag potential outbreak weeks (8). Algorithm details are provided in the Appendix (https:// wwwnc.cdc.gov/EID/article/26/9/191315-App1.pdf).

To account for seasonal variability, nonbloody ADD cases for each week during 2009-2011 (36 months) were compared with an 8-week sliding historical baseline calculated from the current and previous 2 years $(10,11)$. We excluded signals from weeks with $<5$ cases to minimize false signals associated with epidemiologic silence. Because of

${ }^{1}$ These first authors were co-principal investigators and contributed equally to this article. 
ADD's <1-week incubation period, we did not consider buffer intervals, except when implementing the C3 CUSUM-like algorithm, which sums positive differences in cases from the mean for the past 3 periods. We optimized X-bar k, EWMA k and $\lambda$, and CUSUM $k$ and $h$ by exploring $X$-bar and EWMA $\mathrm{k}$ and CUSUM $\mathrm{h}$ values ranging from 2 to 6 , CUSUM $\mathrm{k}$ values 1 to 3.5 , and $\lambda$ values 0.25 to 0.5 , choosing parameters to maximize specificity and positive predictive value (PPV) while maintaining perfect sensitivity in predicting outbreaks at a randomly selected site (Policlínico Naval Ancón) (7). We calculated algorithm sensitivity, specificity, and PPV and compared each model's performance by using pairwise exact McNemar tests with Bonferroni correction, using data from 5 sites capable of confirming true outbreaks through epidemiologic links (517 site-weeks). We performed all analyses in $\mathrm{R}$ version 3.6.3 (https:/ / cran.r-project.org/bin/ windows/base/old/3.6.3); p values $<0.05$ were considered statistically significant.

During 2007-2011, a total of 144 sites reported 48,409 ADD cases, $98 \%$ of which were nonbloody. A total of 8,860 nonbloody cases were reported from 91 sites in 2007, 10,775 cases from 101 sites in 2008, 9,347 cases from 107 sites in 2009, 9,698 cases from 120 sites in 2010, and 8,588 cases from 118 sites in 2011 . Of all these cases, $87 \%$ occurred in persons $\geq 5$ years of age, $9 \%$ in children $1-4$ years of age, and $4 \%$ in children $<1$ years of age. During 2007-2011, nonbloody ADD incidence peaked in 2008 at 305.2 cases/1,000 population (Figure 1). Seasonal incidence was higher during Peru's summer months (median 14.3 cases/1,000 population), January through March, compared with other months (median 12.5 cases $/ 1,000$ population; $p=0.0003$ ).

The median proportion of weeks during which a site reported $\geq 1$ ADD case was 19\% (interquartile range [IQR] $5 \%-44 \%$ ), and the median length of epidemiologic silence was 58 weeks (IQR 13-147 weeks). We observed no statistically significant difference in the proportion of weeks with $\geq 1$ ADD case between sea-based and shore-based sites $(p=0.55)$.

We established the aberration detection algorithm by using 6,962 site-weeks of data from the 45 sites with $<4$ months of epidemiologic silence during 2007-2011 (Table). These reporting sites consisted of 15 ships and 30 land bases from 20 districts within 14 provinces. Site populations ranged from 35 to 10,000 (median 210, IQR 93.75-450). Algorithm parameter sensitivity analysis yielded optimal results when $X$ bar $\mathrm{k}=4.5$, EWMA $\mathrm{k}=4$ and $\lambda=0.25$, and CUSUM $\mathrm{k}=1.5$ and $\mathrm{h}=3$ (Appendix Figures 1-3).

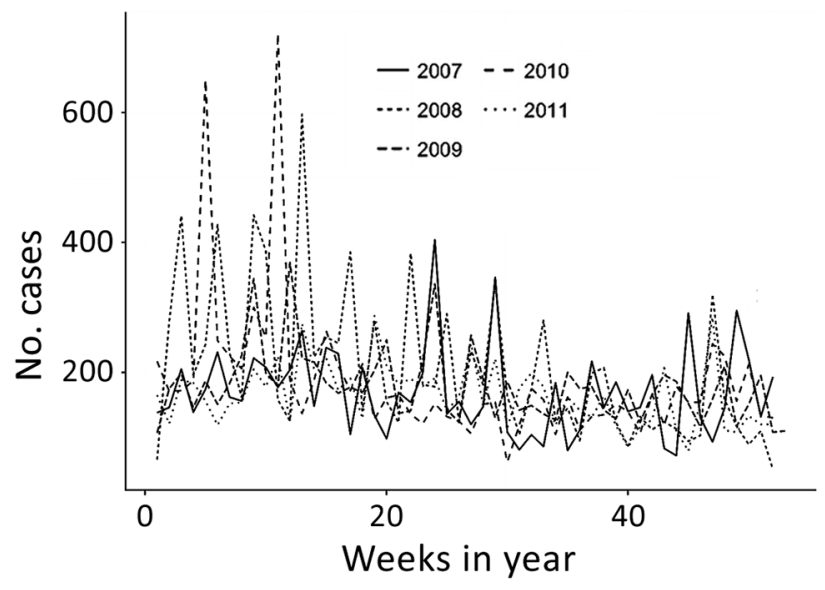

Figure 1. Epidemic curve for nonbloody acute diarrheal disease cases, by week, captured by the Alerta and Vigila Systems, Peru, 2007-2011.

We estimated algorithm sensitivity, specificity, and PPV by categorizing 785 weeks of data into positive and negative outbreak weeks and comparing each algorithm's outbreak predictions with data from the 5 sites capable of confirming true outbreaks during 2009-2011 (Figure 2). X-bar produced 13 signals, EWMA 13 signals, and CUSUM 20 signals. Six true outbreaks occurred (Table); all were detected by X-bar, EWMA, and CUSUM algorithms, corresponding to $100 \%$ sensitivity for each algorithm. Algorithm specificity across the 5 sites was $99.1 \%$ for X-bar, $99.1 \%$ for EWMA, and $98.2 \%$ for CUSUM. PPV was $46.2 \%$ for X-bar, $46.2 \%$ for EWMA, and $30 \%$ for CUSUM. X-bar and EWMA each produced 7 false-positives, and CUSUM produced 14 false-positives. The performance differences were not statistically significant.

\section{Conclusions}

X-bar, EWMA, and C3 CUSUM aberration detection algorithms identified all ADD outbreaks during 2009-2011, and approximately one third to one half of algorithm outbreak signals corresponded to true outbreaks. These findings suggest that these algorithms can usefully inform outbreak asset deployment, particularly in resource-limited settings.

Overall, X-bar and EWMA performed marginally better than CUSUM (PPV 46\% vs. 30\%). CUSUM frequently produced false-positives in the weeks after large outbreaks (e.g., after the 76-case outbreak at Policlínico Naval Ancón) (Table). X-bar's successful detection of ADD in the context of weekly reporting schedules and short disease incubation periods is consistent with its design, which favors detection of events lasting 1 epidemiologic period. In contrast, 
Table. Nonbloody acute diarrheal disease case count and incidence, 2007-2011, and true outbreak detection data and algorithm performance, 2009-2011, for the 45 naval surveillance sites in Peru, analyzed by using X-bar chart, exponentially weighted moving average, and Early Aberration Reporting System C3 cumulative sums models*

\begin{tabular}{|c|c|c|c|c|}
\hline Surveillance site & $\begin{array}{l}\text { Total cases, } \\
2007-2011\end{array}$ & $\begin{array}{c}\text { Average } \\
\text { cases/week/1,000 } \\
\text { population, 2007-2011 }\end{array}$ & $\begin{array}{l}\text { Date of true outbreak } \\
\text { detection, case count, } \\
\text { incidence, 2009-2011 }\end{array}$ & $\begin{array}{l}\text { Average outbreak detection } \\
\text { algorithm performance, } \\
\text { 2009-2011 }\end{array}$ \\
\hline BAP Aguirre & 393 & 13.45 & $\begin{array}{l}2009 \text { Jan } 24,25 \text { cases, } \\
109 / 1,000 \text { population }\end{array}$ & $\begin{array}{c}\text { Sensitivity } 100 \% \text {, specificity } \\
97.4 \% \text {, PPV } 20.0 \%\end{array}$ \\
\hline BAP Bolognesi & 334 & 11.04 & $\ddagger$ & $\ddagger$ \\
\hline BAP Carvajal & 581 & 14.56 & $\ddagger$ & $\ddagger$ \\
\hline BAP Eten & 129 & 27.95 & $\ddagger$ & $\ddagger$ \\
\hline BAP Grau & 887 & 9.04 & $\ddagger$ & $\ddagger$ \\
\hline BAP Mariátegui & 490 & 16.64 & $\ddagger$ & $\ddagger$ \\
\hline BAP Montero & 321 & 12.39 & $\ddagger$ & $\ddagger$ \\
\hline BAP Paita & 185 & $\dagger$ & $\ddagger$ & $\ddagger$ \\
\hline BAP Palacios & 1,118 & 27.16 & $\ddagger$ & $\ddagger$ \\
\hline BAP Pisagua & 224 & 55.04 & & \\
\hline BAP Pisco & 283 & + & & \\
\hline BAP Quiñones & 289 & 9.17 & & \\
\hline BAP Sánchez Carrión & 156 & 39.90 & $\ddagger$ & $\ddagger$ \\
\hline BAP Velarde & 114 & 36.54 & $\begin{array}{l}2011 \text { Sep } 5,12 \text { cases, } \\
250 \text { cases } / 1,000 \\
\text { population }\end{array}$ & $\begin{array}{c}\text { Sensitivity } 100 \% \text {, specificity } \\
100 \% \text {, PPV } 100 \%\end{array}$ \\
\hline BAP Villavicencio & 251 & 9.20 & $\ddagger$ & $\ddagger$ \\
\hline Base Aeronaval & 991 & 4.19 & $\ddagger$ & $\ddagger$ \\
\hline Base Naval Chimbote & 349 & 4.90 & $\ddagger$ & $\ddagger$ \\
\hline Base Naval Nanay & 596 & 4.54 & $\ddagger$ & $\ddagger$ \\
\hline Base Naval San Juan & 313 & 25.74 & $\ddagger$ & $\ddagger$ \\
\hline BCT Aguaytia & 214 & 39.81 & $\ddagger$ & $\ddagger$ \\
\hline BCT Contamana & 261 & $\dagger$ & & \\
\hline BCT Huipoca & 154 & 46.81 & $\ddagger$ & $\ddagger$ \\
\hline BCT San Alejandro & 118 & 26.22 & $\ddagger$ & $\ddagger$ \\
\hline Capitanía Puerto Mollendo & 171 & 19.52 & $\ddagger$ & $\ddagger$ \\
\hline Capitanía Puerto Puno & 246 & 26.74 & $\ddagger$ & $\ddagger$ \\
\hline Centro Instrucción Técnica Naval & 829 & 3.48 & $\ddagger$ & $\ddagger$ \\
\hline Clínica Naval de Iquitos & 3,269 & 1.84 & $\ddagger$ & $\ddagger$ \\
\hline Comandancia Primera Zona Naval & 244 & 21.02 & \pm & $\stackrel{+}{\ddagger}$ \\
\hline Comandancia Tercera Zona Naval & 625 & 21.48 & $\begin{array}{l}2010 \text { Aug } 14,31 \text { cases, } \\
207 \text { cases } / 1,000 \\
\text { population }\end{array}$ & $\begin{array}{c}\text { Sensitivity } 100 \% \text {, specificity } \\
99.4 \%, \text { PPV }, 50.0 \%\end{array}$ \\
\hline $\begin{array}{l}\text { Dirección de Capitanías y } \\
\text { Guardacostas }\end{array}$ & 293 & 5.77 & $\ddagger$ & $\ddagger$ \\
\hline Dirección de Hidrografía y Navegación & 385 & 8.09 & $\ddagger$ & $\ddagger$ \\
\hline Escuela Naval & 988 & 4.84 & \pm & \pm \\
\hline Estación Naval Isla San Lorenzo & 449 & 24.34 & $\ddagger$ & $\ddagger$ \\
\hline Estación Naval Mollendo & 343 & 6.42 & $\stackrel{\ddagger}{\ddagger}$ & $\begin{array}{l}+ \\
\ddagger\end{array}$ \\
\hline Estación Naval Paita & 796 & 8.93 & $\stackrel{\ddagger}{\ddagger}$ & $\stackrel{+}{\ddagger}$ \\
\hline Estación Naval Pucallpa & 2,098 & 15.22 & $\begin{array}{l}+ \\
\ddagger\end{array}$ & $\stackrel{+}{\ddagger}$ \\
\hline Estación Naval Submarinos & 734 & 16.33 & $\begin{array}{c}2010 \text { Feb } 8,21 \text { cases, } \\
100 \text { cases } / 1,000 \\
\text { population }\end{array}$ & $\begin{array}{c}\text { Sensitivity } 100 \% \text {, specificity } \\
99.1 \% \text {, PPV } 42.9 \%\end{array}$ \\
\hline $\begin{array}{l}\text { Estación Naval de la Comandancia } \\
\text { General }\end{array}$ & 1,260 & $\dagger$ & $\ddagger$ & $\ddagger$ \\
\hline Hospital Base Naval del Callao & 4,132 & 1.62 & $\ddagger$ & $\ddagger$ \\
\hline Policlínico Naval Ancón & 2,019 & 5.24 & $\begin{array}{c}2010 \text { Feb } 11,33 \text { cases } \\
18 \text { cases } / 1,000 \\
\text { population; } 2010 \text { Feb } \\
20,22 \text { cases, } 12 \\
\text { cases } / 1,000 \text { population }\end{array}$ & $\begin{array}{c}\text { Sensitivity } 100 \% \text {, specificity } \\
98.1 \% \text {, PPV } 40.0 \%\end{array}$ \\
\hline Policlínico Naval San Borja & 2,892 & 134.51 & $\ddagger$ & $\ddagger$ \\
\hline Posta Naval de Ventanilla & 1,110 & 113.15 & $\ddagger$ & $\ddagger$ \\
\hline Villa Naval de Tumbes-El Salto & 710 & $\dagger$ & $\ddagger$ & $\ddagger$ \\
\hline
\end{tabular}



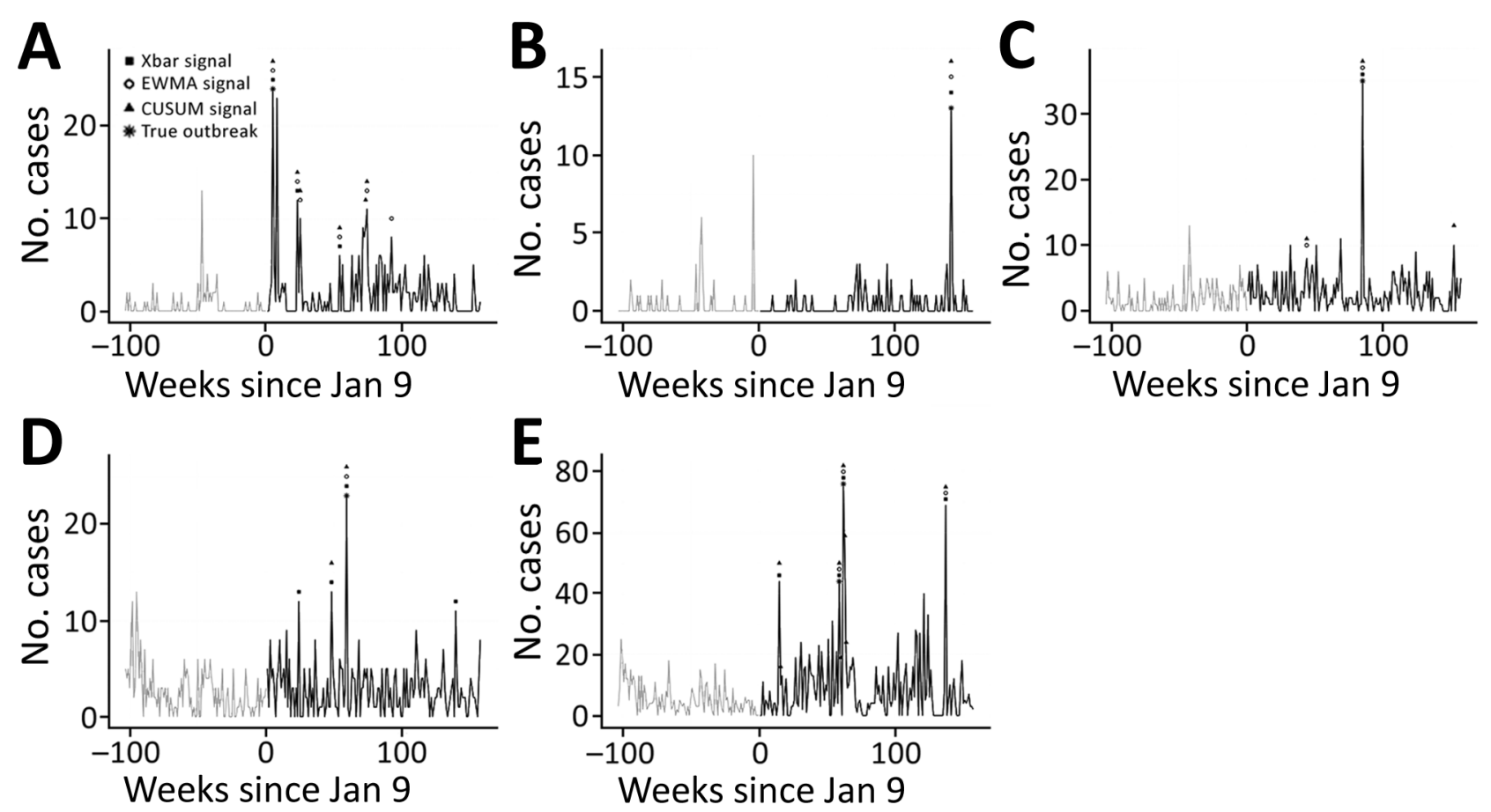

Figure 2. Epidemic curves for nonbloody acute diarrheal disease over time, demonstrating outbreaks identified by the Alerta and Vigila Systems, by identifying algorithm and surveillance site, Peru, 2009-2011. A) Buque de la Armada Peruana Aguirre; B) BAP Velarde; C) Comandancia Tercera Zona Naval; D) Estación Naval Submarinos; and E) Policlínico Naval Ancón. Shapes correspond with identifying algorithms; asterisks indicate outbreaks confirmed through epidemiologic links (i.e., true positives). CUSUM, C3 cumulative sums; EWMA, exponentially weighted moving average.

EWMA and CUSUM were designed for earlier detection of consecutive small baseline deviations (12). Whereas EWMA can be tuned to favor shorter outbreaks through its weighting parameter $(\lambda)$, the $C 3$ CUSUM algorithm is more rigid. In the context of weekly ADD reporting, EWMA and CUSUM algorithm performance might improve by counting consecutive weeks with outbreak signals as a single alert.

Our study has limitations, including the number of sites capable of confirming outbreaks, which reduced the statistical power to detect differences between algorithms, and the inability to distinguish a lack of reporting versus a lack of ADD cases to report during periods of epidemiologic silence. Combined, these factors limited the evaluation to 3,925 site-weeks of observation, reducing the reliability of algorithm parameter estimates. Furthermore, model parameters were established on only 1 of the 5 evaluation sites; a larger development set would better optimize model parameters while avoiding overfitting.

Characterizing algorithm parameter tradeoffs might aid system capability alignment with health priorities. Lower detection thresholds are advantageous for high-risk diseases with distinct syndromes, such as cholera, Ebola, and Middle East respiratory syndrome. Conversely, changing parameters, such as changing EWMA's weighting parameter $(\lambda)$, can affect algorithm PPV (increasing to $>60 \%$ during sensitivity analysis). Context-focused exploration could inform which parameters should be tuned to improve PPV, sensitivity, or specificity. Because smaller populations and stable disease baselines improve algorithm performance, tuning algorithm parameters for specific sites during implementation by using historical data might improve overall system performance, as might periodic evaluation of model assumptions, parameter tuning, and model performance.

The views expressed in this article are those of the authors and do not necessarily reflect the official policy or position of the Department of the Navy, Department of Defense, nor the governments of the United States or Peru.

Several authors of this manuscript are employees of the US Government. This work was prepared as part of their duties. Title 17 U.S.C. § 105 provides that "Copyright protection under this title is not available for any work of the United States Government." Title 17 U.S.C. § 101 defines a US Government work as a work prepared by a military service member or employee of the US Government as part of that person's official duties. 


\section{About the Author}

Ms. Alsentzer is a PhD student in the Harvard-MIT

Program in Health Science and Technology. Her background is in computer science and biomedical informatics, and her research focuses on machine learning applications to healthcare. Dr. Ballard is a medical epidemiologist in the Epidemic Intelligence Service at the Centers for Disease Control and Prevention. Her background is in tropical diseases, surveillance, and global public health.

\section{References}

1. Henning KJ. Overview of syndromic surveillance: what is syndromic surveillance? MMWR Morb Mortal Wkly Rep. 2004;53(Suppl):5-11.

2. Margevicius KJ, Generous N, Abeyta E, Althouse B, Burkom H, Castro L, et al. The Biosurveillance Analytics Resource Directory (BARD): facilitating the use of epidemiological models for infectious disease surveillance. PLoS One. 2016; 11:e0146600. https://doi.org/10.1371/journal.pone.0146600

3. Blazes DL, Lewis SH. Disease surveillance: technological contributions to global health security. Boca Raton (Florida): CRC Press; 2016. p. 120-1.

4. Soto G, Araujo-Castillo RV, Neyra J, Fernandez M, Leturia C, Mundaca CC, et al. Challenges in the implementation of an electronic surveillance system in a resource-limited setting: Alerta, in Peru. BMC Proc. 2008; 2(Suppl 3):S4. https://doi.org/10.1186/1753-6561-2-s3-s4

5. Burkom H. Development, adaptation, and assessment of alerting algorithms for biosurveillance. Johns Hopkins APL Tech Dig. 2003;24:335-42 [cited 2020 Apr 4]. https:/ / www.jhuapl. edu/content/techdigest/pdf/v24-n04/24-04-burkom.pdf

6. Hutwagner L, Thompson W, Seeman GM, Treadwell T. The bioterrorism preparedness and response Early Aberration Reporting System (EARS). J Urban Health. 2003;80(Suppl 1):i89-i96.

7. Fricker RD Jr, Hegler BL, Dunfee DA. Comparing syndromic surveillance detection methods: EARS' versus a CUSUM-based methodology. Stat Med. 2008;27:3407-29. https://doi.org/10.1002/sim.3197

8. Fricker R. Introduction to statistical methods for biosurveillance: with an emphasis on syndromic surveillance. Cambridge: Cambridge University Press; 2013. p. 178-215.

9. Hutwagner LC, Thompson WW, Seeman GM, Treadwell T. A simulation model for assessing aberration detection methods used in public health surveillance for systems with limited baselines. Stat Med. 2005;24:543-50. https:/ / doi.org/ 10.1002/sim.2034

10. Murphy SP, Burkom H. Recombinant temporal aberration detection algorithms for enhanced biosurveillance. J Am Med Inform Assoc. 2008;15:77-86. https:/ / doi.org/10.1197/ jamia.M2587

11. Mathes RW, Lall R, Levin-Rector A, Sell J, Paladini M, Konty KJ, et al. Evaluating and implementing temporal, spatial, and spatio-temporal methods for outbreak detection in a local syndromic surveillance system. PLoS One. 2017;12:e0184419. https://doi.org/10.1371/journal.pone.0184419

12. Lombardo J. Disease surveillance: a public health approach. Hoboken (NJ): John Wiley \& Sons, Inc.; 2007. p. 158.

Address for correspondence: Sarah-Blythe Ballard, Centers for Disease Control and Prevention, 1600 Clifton Rd NE, Mailstop H24-3, Atlanta, GA 30029-4027, USA; email: sballar3@jhu.edu

\section{EID podcast An Increase in Streptococcus pneumoniae
Serotype $12 \mathrm{~F}$}

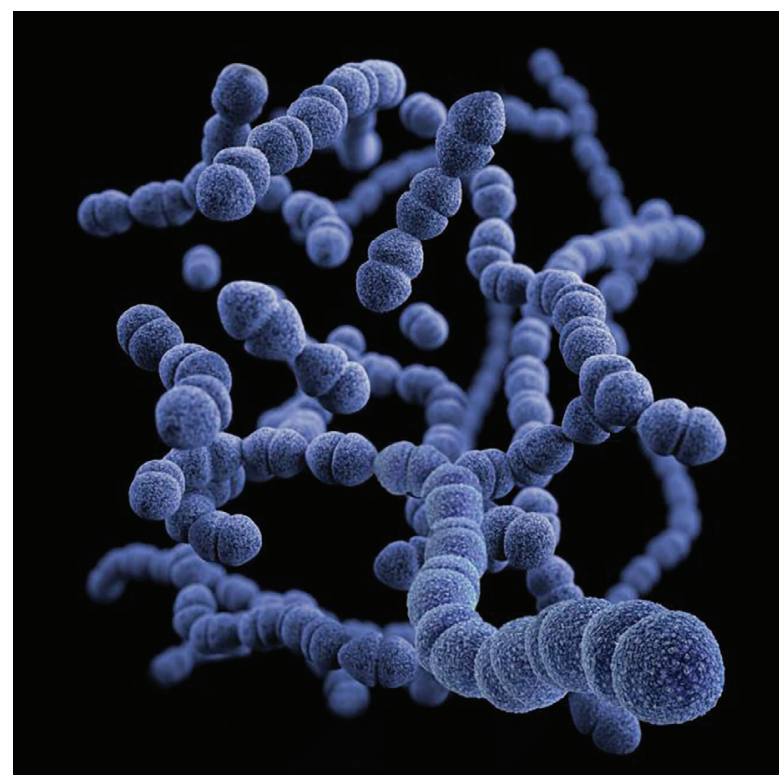

In 2009, Israel introduced a vaccine designed to protect against multiple strains of pneumococcal disease. Even though the vaccine prevented certain strains of the illness, one uncovered serotype increased in frequency.

In this EID podcast, Dr. Cynthia Whitney, a CDC epidemiologist, discusses an increase in serotype $12 \mathrm{~F}$ pneumoniae in Israel.

Visit our website to listen: https: //go.usa.gov/xy6AM EMERGING INFECTIOUS DISEASES 